

\title{
Rendimento de hidrólise e produção de etanol lignocelulósico a partir de biomassa de capim elefante
}

\author{
Yield of hydrolysis and production of lignocellulosic ethanol from elephant grass \\ biomass
}

OPPEN ACCESS
Lara Neiva de Siqueira ${ }^{1, \text { ID }}$
Emerson Adriano Guarda ${ }^{1, * \text { (DD }}$
Patrícia Martins Guarda1,(iD)
Roseanne Batista Rodrigues da
Silva ${ }^{1,(D D}$
Robson dos Santos Barbosa ${ }^{1,(D D}$
* Autor para correspondência:
emersonprof@mail.uft.edu.br
1 Universidade Federal do Tocantins (UFT)
Informações adicionais

Recebido em: 14/07/2016

Aceito em: 20/10/2016

Publicado em: 20/12/2016

Editor:

Victor Hugo Gomes Sales

Instituto Federal do Amapá. Macapá, AP. jbfs@ifap.edu.br

\section{Avaliação às cegas por pares}

Processos de revisão

Prot. 1122016R01 (Brasil)

Prot. 1122016R02 (Brasil)

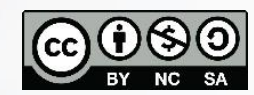

JBFS all rights

Copyright: 〔 2016

\begin{abstract}
ID JBFS1122016
DOI 10.18067/jbfs.v3i4.112

\section{RESUMO}

Devido à busca por biomassas alternativas, de fácil acesso, baixo custo e com alta concentração de celulose para produção de etanol de 2a geração - ou lignocelulósico - realizou-se este estudo com o Pennisetum purpureum, conhecido como capim elefante. O estudo foi conduzido com objetivo de determinar a composição química da forragem do capim elefante para avaliar seu uso na produção de etanol lignocelulósico. As hastes de capim elefante foram colhidas em área experimental da Feira Agrotecnológica de Palmas AGROTINS, no mês de agosto de 2015. Os resultados observados mostraram que o capim elefante apresentou aproximadamente $60 \%$ de celulose, demonstrando o potencial de utilização desta biomassa para obtenção de açúcares redutores. A biomassa passou por pré-tratamento químico antes da etapa de hidrólise enzimática, utilizando-se enzima comercial celulase Cellic CTEC2. Após a hidrólise, obteve-se um rendimento de $54 \%$ em açúcares redutores, obtendo-se rendimento na hidrólise de $53,9 \%$. O rendimento da produção de etanol foi de $87,8 \%$. A partir disso, pode-se afirmar que a biomassa capim elefante possui grande potencial como fonte de celulose, podendo ser uma alternativa barata e de grande disponibilidade para produção de etanol lignocelulósico.
\end{abstract}

Palavras-chave: Etanol de segunda geração. Celulose. Lignina. Hidrólise enzimática.

\section{ABSTRACT}

Due to search for alternative biomasses, that are easy to access, low cost and high in cellulose concentration, for the production of 2 nd generation ethanol or lignocellulosic - this study was carried out with Pennisetum purpureum, known as elephant grass. The study was conducted to determine the chemical composition of elephant grass forage to evaluate its use in the production of lignocellulosic ethanol. The elephant grass stems were reaped in the experimental area of Feira Agrotecnológica de Palmas (AGROTINS) on august 2015. The results have shown that the elephant grass presented approximately $60 \%$ cellulose, demonstrating the potential use of this biomass to obtain reducing sugars. The biomass underwent chemical pretreatment before the enzymatic hydrolysis step using commercial cellulase enzyme Cellic CTEC2. After hydrolysis, gave a $54 \%$ yield of reducing sugars, which has shown a yield of $53,9 \%$ in the hydrolysis. In addition, the yield for ethanol production was $87,8 \%$. Due to this, it is possible to assure that the elephant grass biomass has a great potential as cellulose source, therefore it can be used as an alternative that is cheap and huge in availability to the production of lignocellulosic ethanol.

Keywords: Second generation ethanol. Cellulose. Lignin. Enzymatic hydrolysis. 


\section{INTRODUÇÃO}

A agricultura no Brasil tem passado por muitas mudanças devido às constantes discussões ligadas a questões ecológicas, econômicas e sociais. Sendo assim, a modernização da agricultura foi impulsionada pelo rápido crescimento da população, demanda alimentar e energética para garantir a sobrevivência. Neste cenário, houve, nos últimos 30 anos, expressivo aumento do uso de insumos químicos na agricultura pela expansão da produtividade e pelo uso de estratégias no processo de comercialização. ${ }^{1}$

A produção de biocombustíveis está diretamente relacionada à modernização da agricultura e, segundo ${ }^{1}$ a utilização dos biocombustíveis ou matrizes energéticas renováveis, vem ocupando muita atenção de investidores internacionais, devido aos resultados experimentais que propõem queda nas emissões de $\mathrm{CO}_{2}$ e, consequentemente, redução do efeito estufa pelo uso destas fontes e pelo cenário de constantes variações no preço do petróleo.

Os biocombustíveis podem ser produzidos a partir de matérias primas de origem vegetal, como plantas de origem animal, como o sebo bovino, que é utilizado na produção de biodiesel; além de outras fontes residuais da indústria, da agropecuária ou florestal. A exemplo, a produção de álcool combustível da cana-de-açúcar no Brasil ${ }^{2}$ - na Europa, é produzido pelo processamento da beterraba - ou do amido (milho, trigo, raízes e tubérculos). ${ }^{3}$

Segundo Nunes et.al. ${ }^{4}$, para a produção do etanol de segunda geração, utilizam-se materiais lignocelulósicos, assim, podem-se utilizar diversos resíduos agrícolas ou excedentes de atividades agrícolas, em que, por meio de tratamentos químicos, termoquímicos ou rotas bioquímicas, obtém-se o produto-alvo, aperfeiçoando o processo de eficiência e reduzindo impactos ambientais, como a poluição do ar atmosférico pela eliminação de $\mathrm{CO}_{2}$ por veículos automotores.

O biopolímero que mais está presente na parede celular das células vegetais é a celulose. ${ }^{5}$ Muitos pesquisadores estudam sobre os meios para obtenção de etanol, a partir da celulose, o qual demanda vários processos, a citar: pré-tratamento da biomassa, que pode incluir quebra da parede celular (para um melhor aproveitamento da celulose disponível), isolamento dos açúcares e lignina e, posteriormente, ocorre o processo de fermentação. ${ }^{6}$

O capim elefante (Pennisetum purpureum) tem sido objeto de vários tipos de estudos, sendo amplamente utilizado para produção de energia, a exemplo, há a utilização de pellets para geração de bioeletricidade, a partir da queima em caldeiras. ${ }^{7}$

O uso dos biocombustíveis de segunda geração pode não substituir totalmente $\mathrm{o}$ uso de energia proveniente de fontes não renováveis, mas pode contribuir social e economicamente para o país e evitar o esgotamento destas fontes de energia. $\mathrm{O}$ presente trabalho tem por objetivo determinar a composição química da forragem do capim elefante, para avaliar seu uso na produção de etanol lignocelulósico. Esse vegetal pode ser encontrado no estado de Tocantins.

\section{MATERIAL E MÉTODOS}

As hastes de capim elefante foram colhidas em área experimental da Feira Agrotecnológica de Palmas AGROTINS, no mês de agosto de 2015. O clima predominante é o tropical, com domínio morfoclimático do cerrado, sendo que, o índice pluviométrico é de 1300 milímetros anuais. $O$ mês mais chuvoso é Janeiro, quando chove $246 \mathrm{~mm}$, enquanto o mês mais seco é julho, quando a chuva é quase nula.

O capim elefante, Cultivar Napier, teve os cortes realizados a $15 \mathrm{~cm}$ do solo, sendo que, as hastes escolhidas foram de perfilhos jovens e velhos, pois não havia informações acerca da quantidade de cortes ou mesmo queimas, uma vez que a área já havia sido submetida a essa ação natural, já que existe uma tendência de queima de pastagens no Estado do Tocantins, que, em sua maioria, toma-se descontrolada e invade plantações e áreas de consevação.

\section{A) Determinação do Teor de Lignina}

O teor de Lignina foi determinado de acordo com metodologias realizadas pelo Centro Nacional de Pesquisa do Algodão, Campina Grande, PB. ${ }^{8}$ Tomou-se $1,0 \mathrm{~g}$ da amostra seca em estufa a aproximadamente $60^{\circ} \mathrm{C}$ e moída em moinho de facas tipo Willye. Em seguida, o material foi colocado em um almofarize adicionado de $17,0 \mathrm{ml}$ de ácido sulfúrico $72,0 \%(\mathrm{~m} / \mathrm{m})$, resfriado em geladeira de 10 a $15^{\circ} \mathrm{C}$, antes do uso. Agitou-se vigorosamente o material com o pistilo, até total homogeneização, formando-se uma pasta. A digestão da amostra ocorreu por 24 horas.

Após a digestão, o ácido sulfúrico foi diluído a 4,0\%, e todo o conteúdo foi transferido para um balão de $1.000 \mathrm{ml}$. A amostra foi mantida sob refluxo por 4 horas.

Todo o conteúdo do balão foi filtrado e levado à estufa a $105 \pm 2{ }^{\circ} \mathrm{C}$ até massa constante. Após secagem em estufa o material foi levado à mufla para determinação do teor de cinzas.

O teor de Lignina foi calculado utilizando-se as seguintes equações:

Teor de Cinza $\%=\frac{M F C-M F}{M A} \times 100$ 
Teor de Lignina $\%=\left(\frac{M F L-M F}{M A} X 100\right)-T C$

(Eq. 2)

Onde:

MF: massa do funil limpo e seco (g);

MA: massa da amostra (g);

MFL: massa do funil + lignina após secagem em estufa (g);

MFC: massa do funil + cinzas após calcinação em mufla (g);

TC: teor de cinzas (\%).

\section{B) Determinação do Teor de Celulose}

O teor de celulose foi determinado, segundo metodologia utilizada pela Embrapa, Clima Temperado, Pelotas, RS. ${ }^{9}$ Pesou-se em tubo de ensaio $1,0 \mathrm{~g}$ da amostra seca em estufa a aproximadamente $60^{\circ} \mathrm{C}$ e moída em moinho de facas tipo Willye, em seguida, foi adicionado 16,5 $\mathrm{ml}$ de reagente ácido, previamente preparado com ácido acético glacial (72,73\%), água destilada (18,18\%) e ácido nítrico (9,09\%).

Para a etapa de digestão das proteínas a amostra foi colocada em banho-maria, em ebulição, por trinta minutos. Após a digestão, foram adicionados $20 \mathrm{ml}$ de álcool etílico, em seguida, todo o material foi filtrado e lavado com $20 \mathrm{ml}$ de etanol quente, adicionou-se na filtração $20 \mathrm{ml}$ de benzeno quente e, finalmente, $20 \mathrm{ml}$ de éter sulfúrico, à $65^{\circ} \mathrm{C}$.

O conteúdo filtrado foi levado à estufa a $105 \pm 2^{\circ} \mathrm{C}$ até peso constante e à mufla, para determinação do teor de cinzas.

O teor de Celulose foi calculado utilizando-se a seguinte equação:

Teor de Celulose $\%=\left(\frac{M_{i}-M P-M_{f}}{M A}\right) \times 100$

(Eq. 3)

Onde:

MA: Massa da amostra (g);

Mi: Massa do cadinho + amostra após secagem (g);

MP: Massa do papel filtro (g);

Mf: Massa do cadinho + cinzas (g).

C) Pré-tratamento

O material passou por pré-tratamento, segundo metodologia de Menezes e Hennies, ${ }^{10}$ no qual se utilizou uma solução de hidróxido de sódio 4,0\% , que foi adicionada à $100 \mathrm{~g}$ de biomassa de capim elefante (base seca - b.s.), na condição de 1:20 (m/v), que foi submetido, por 15 minutos, ao autoclave a $121^{\circ} \mathrm{C}$. O material obtido foi levado a um agitador magnético e adicionou-se ácido fosfórico (p.a) até que se obteve um $\mathrm{pH} 2,0$ (dois), dessa forma, a mistura ficou em reação por 30 minutos, passadoeste tempo, o conteúdo foi neutralizado com hidróxido de sódio (p.a).

O material foi filtrado, e em seguida um volume proporcional de água destilada foi adicionado ao volume do material e essa mistura foi novamente autoclavada a $121^{\circ} \mathrm{C}$ por 15 minutos. A suspensão foi filtrada e o material foi desidratado na estufa a $65^{\circ} \mathrm{C}$ até massa constante, obtendo assim $68,0965 \mathrm{~g}$ da biomassa seca pré-tratada (rendimento de $68,09 \%$ ). A biomassa foi desidratada pela facilidade de armazenamento, nestas condições, em dessecador contendo sílica gel.

\section{D) Hidrólise Enzimática}

Visando a avaliar o potencial para produção de etanol de uma maneira mais simples e de baixo valor, deuse início ao processo de hidrólise enzimática celulolítica adicionando-se $1,0000 \mathrm{~g}$ de biomassa seca a $50 \mathrm{ml}$ de água destilada em um balão volumétrico, sob agitação durante 1hora.

Em seguida, corrigiu-se o pH para 5 (cinco) e adicionou-se, então, a enzima comercial Cellic Htec2 (Novozymes) à temperatura de $50-55^{\circ} \mathrm{C}$, sob agitação constante por 72 horas.

\section{E) Fermentação}

Após a hidrólise enzimática, a fase líquida foi fermentada com a levedura comercial Saccharomyces cerevisiae (Fleischmann ${ }^{\circledR}$ ), para tanto, ajustou-se o pH das amostras e adicionou-se aproximadamente $0,09 \mathrm{~g}$ da levedura, em $20 \mathrm{ml}$ de amostra hidrolisada, permanecendo em reação a aproximadamente $30^{\circ} \mathrm{C}$ por 24 horas.

Nenhuma alteração foi feita para o processo fermentativo, como utilização de sais e nutrientes para enriquecimento do meio.

\section{F) Análise por Cromatografia Líquida de Alta Eficiência - CLAE}

A análise cromatográfica das substâncias (carboidratos e etanol) foi realizada em um cromatógrafo líquido de alta eficiência, marca Shimadzu (LC-10 Series Avp; desgaseificador: DGU-14A, integrador: CLASS LC-10), com eluição isocrática pelo bombeamento (LC-10AD) de uma fase móvel, composta de $5 \mathrm{mM}$ de ácido sulfúrico em água ultrapura. A vazão do eluente foi de $0,6 \mathrm{ml} / \mathrm{min}$, a $35^{\circ} \mathrm{C}$ (forno de coluna CTO-10A), com corrida de tempo total de 25 minutos. A detecção se deu em detector de índice de refração (Shimadzu, modelo RID-10A).

Uma alíquota de 20,0 $\mu$ da amostra foi injetada 
manualmente (injetor Rheodyne -iL malha 20) e permeada por uma coluna de exclusão iônica da marca Phenomenex Rezex ROA-Organic Acid $\mathrm{H}+(300 \times 7,8 \mathrm{~mm})$ com conexão direta a Cartucho de segurança Phenomenex Carbo-H $(4 \times 3 \mathrm{~mm})$ preenchida com material semelhante ao da coluna principal. Padrões de cada substância foram utilizados para construção da curva de calibração, utilizada para calcular a concentração de carboidratos e etanol.

\section{RESULTADOS E DISCUSSÃO}

A biomassa de capim elefante avaliada apresentou $59,3 \% \pm 0,6 \%$ b.s. de celulose e $8,8 \% \pm 0,3 \%$ b.s. de lignina, estes percentuais são bastante promissores, visto que a celulose se encontra acima dos valores médios de outras biomassas residuais comuns, como se pode observar na Tabela 1 exposta. Cabe ressaltar que foram realizados testes desta biomassa, sem a premissa de um pré-tratamento químico e os resultados encontrados foram $40,4 \%$ de celulose e $16,6 \%$ de lignina, respectivamente.

A palha de Cana de açúcar já vem sendo utilizada para produção de etanol e também para cogeração de energia. Logo, os valores obtidos em experimentos, no que tange à produção de etanol, a partir da palha da cana de açúcar, já são considerados como promissores, já que para 1 tonelada de palha de cana de açúcar, estima-se uma produção de 287 litros de etanol. ${ }^{11}$

Tabela 1. Composição química de biomassas lignocelulósicas com potencial para produção de etanol de segunda geração.

Table 1. Chemical composition of lignocellulosic biomass with potential for second generation ethanol.

\begin{tabular}{lcc}
\hline \multicolumn{1}{c}{$\begin{array}{c}\text { Biomassa } \\
\text { lignocelulósica }\end{array}$} & \% Celulose & \% Lignina \\
\hline Palha de Cana & $40-44$ & $22-25$ \\
Bagaço de Cana & $32-49$ & $23-33$ \\
Talo de Milho & 35 & 35 \\
Espiga de Milho & 45 & 15 \\
Algodão & 95 & 0,3 \\
Palha de Trigo & 30 & 15 \\
Palha de Arroz & 43,3 & 16,3 \\
Forragem de Milho & $38-40$ & $7-21$ \\
Fibra de Coco & $36-43$ & $41-45$ \\
\hline
\end{tabular}

Fonte: SANTOS ${ }^{11}$

Source: SANTOS ${ }^{11}$

No Estado do Tocantins, há uma produção expressiva de Arroz (489.577 Ton.), logo o volume de palha desta biomassa ébastante elevado, assim como há uma boa e expressiva produção de milho (350.669 ton.). ${ }^{12}$ Observando a Tabela 1 pode-se inferir que os resíduos: talo de milho, espiga de milho, palha de arroz e forragem de milho, que são encontrados de maneira abundante no Estado, possuem valores percentuais de celulose abaixo dos valores encontrados para o capim elefante.

O CQBAL - Tabelas Brasileiras de Composição de Alimentos para Ruminantes - traz estudos determinantes do valor nutritivo e acerca da composição química dos alimentos. São estudos da composição químicobromatológica dos principais alimentos utilizados em dietas para ruminantes no Brasil. Os valores obtidos para a celulose nas análises laboratoriais no Estado do Tocantins, quando se avalia a biomassa de capim elefante, não tratada quimicamente, estão próximos aos valores encontrados na página do software CQBAL 3.0, que apresenta, para o capim elefante (Pennisetum purpureum), 41,9\% de celulose e 6,8\% de lignina. ${ }^{13}$

Possivelmente, o pré-tratamento utilizado neste estudo determinou um rompimento da macromolécula de lignina e hemicelulose na parte interna da biomassa, o que liberou mais celulose. De acordo com Hamelinck, Van Hooijdonk e Faaij ${ }^{14}$, os pré-tratamentos alcalinos são geralmente mais eficazes na solubilização de uma maior fração da lignina, deixando parte da hemicelulose insolúvel.

Após o pré-tratamento químico, a reação de hidrólise enzimática foi realizada, visando à obtenção de açúcares fermentescíveis para posterior produção de etanol 2G. As concentrações de glicose foram quantificadas a partir da curva padrão de glicose por cromatografia líquida de alta eficiência - CLAE, após 72 horas de hidrólise enzimática da biomassa. Foi considerada nos cálculos a diluição efetuada na amostra, em 1,000 g de capim elefante homogeneizado e diluído para $50 \mathrm{ml}$ com água destilada, a concentração de glicose obtida foi de 7,11 $\pm 1,25 \mathrm{~g} / \mathrm{l}$ (valor médio \pm desvio médio - 3 repetições) representando um rendimento na hidrolise de 22 a $25 \%$.

Considerando o total de celulose na amostra e sua massa inicial, é possível calcular o rendimento das reações de hidrólise. Para isso, tomaram-se os valores máximos obtidos na concentração de glicose e o fator de conversão de glicose em celulose, tal Lu et al. ${ }^{15}$ Os cálculos do rendimento da hidrólise foram realizados pela seguinte equação:

$$
R H(\%)=\left(\frac{[G l i]}{[C e l]} \times 0,9\right) \times 100
$$

Sendo:

RH\%: rendimento da hidrólise em porcentagem;

[Gli.]: concentração de glicose da biomassa (g/l);

[Cel.]: concentração de celulose da biomassa (g/l);

0,9: fator de conversão da celulose. 
O rendimento médio da hidrólise foi de $53,9 \%$, este valor está dentro do padrão apresentado na literatura para outras biomassas lignocelulósicas que visam à produção de etanol, no qual se encontram percentuais de rendimento de hidrólise para a palha de arroz de $52,0 \%{ }^{16}$ e para o bagaço de cana-de-açúcar, em torno de $62,0 \% .{ }^{17}$ Estes resultados demonstram o bom potencial do capim elefante, quando pré-tratado quimicamente na produção de açúcares fermentescíveis.

A fermentação e posterior quantificação do álcool foram um passo adicional a fim de se verificar a capacidade de produção de etanol da biomassa avaliada. A quantificação do álcool se deu através de leituras realizadas por Cromatografia Líquida de Alta Eficiência (CLAE), em que a concentração média de etanol foi de $3,19 \pm 0,48 \mathrm{~g} / \mathrm{l}$ (valor médio \pm desvio médio - 3 repetições), com rendimento de conversão de glicose em etanol de aproximadamente $87,8 \%$, valor que pode ser visto como acima da média, quando comparado com o percentual obtido para outras biomassas, como a palha de arroz, com rendimentos em torno de $40,0-74,0 \%{ }^{18}$

Considerando a concentração de álcool obtida após a fermentação, podemos sugerir uma produção de até $175,9 \mathrm{l} /$ ton de biomassa seca para o Capim elefante, valor significativo, quando comparado a outras biomassas como a palha de cana-de-açúcar e palha de arroz, com produção de álcool de $287 \mathrm{l} /$ ton e $389 \mathrm{l} /$ ton, respectivamente. ${ }^{11}$

\section{CONCLUSÕES}

O capim Elefante torna-se uma boa alternativa para produção de etanol no Estado do Tocantins e no Brasil, pois toda a planta pode ser aproveitada e, além disso, a área plantada para fim de alimentação animal, ainda é pequena no Estado, ficando mais resguardada aos produtores com pouca alternativa para alimentação no período de seca.

Frente a outras biomassas, esse vegetal é de fácil produção, não compete com culturas alimentares e, como fora evidenciado neste trabalho, possui elevado rendimento de hidrólise, superior a 53,0\%, bem como de produção de etanol de 87,0\%. Logo, esta biomassa demonstra elevado potencial, carecendo deestudos mais aprofundados quanto ao seu aproveitamento energético em escalas maiores.

\section{CONTRIBUIÇÃO AUTORES}

Os autores Patrícia Martins Guarda, Roseanne Batista Rodrigues da Silva e Robson dos Santos Barbosa participaram na condução do experimento.

A autora Lara Neiva Siqueira participou no desenvolvimento e condução do experimento; Elaboração do artigo.

O autor Emerson Adriano Guardarealizou o planejamento e a revisão final do artigo.

\section{CONFLITO DE INTERESSE}

Os autores declaram que não há conflito de interesse.

\section{FINANCIAMENTO}

Os autores reportam que não houve suporte e auxílio financeiro durante o desenvolvimento da pesquisa.

\section{COMO CITAR O ARTIGO}

\section{ABNT}

SIQUEIRA, Lara Neiva et al. Rendimento de hidrólise e produção de etanol lignocelulósico a partir de biomassa de capim elefante. Joumal of bioenergy and food science, v.3, n.4, 2016. DOI:10.18067/jbfs.v3i4.112.

\section{APA}

Siqueira, L., Guarda, E., Guarda, P., Silva, R., \& Barbosa, R. (2016). Rendimento de hidrólise e produção de etanol lignocelulósico a partir de biomassa de capim elefante. Journal of Bioenergy and Food Science, 3(4). DOI:10.18067/jbfs.v3i4.112

\section{REFERÊNCIAS}

(1).KOHLHEPP, G. Análise da situação da produção de etanol e biodiesel no Brasil. Estudos avançados, v.24, n.68, p.223-253, 2010. DOI: 10.1590/S0103-40142010000100017

(2).NASS, L. L.; PEREIRA, P. A. A.; ELLIS, D. Biofuels in Brazil: an overview. Crop Science, Madison, v.47, p.2228-2237, 2007. DOI: $10.2135 /$ cropsci2007.03.0166

(3).STEVENSON, D. M.; WEIMER, P. J. Isolation and characterization of a Trichoderma strain capable of fermenting cellulose to ethanol. Applied Biochemistry and biotechnology, v.59, p.721-726, 2002. DOI: 10.1007/s00253-002-1027-3

4. NUNES, R. de M. GUARDA, E. A. SERRA, J. C. V. MARTINS, Á. A. Resíduos agroindustriais: potencial de produção do etanol de segunda geração no Brasil. Revista Liberato, v. 14, n. 22, p. 113-238, 2013.

(5).BOERJAN, W.; RALPH, J.; BAUCHER, M. Lignin biosynthesis. Annual Review of Plant Physiology and Plant Molecular Biology, v.54, p.519-546, 2003. DOI: 10.1146/annurev.arplant.54.031902.134938

(6).RUBIN, E.M. Genomics of cellulosic biofuels. Nature, v.454, n.7206, p.841-845, 2008. DOI: 10.1038/nature07190

(7).GARCIA, D. P. As indústrias de pellets no Brasil: o Brasil tem tudo para ser líder mundial neste segmento. Revista da Madeira, 133. ed., 2012.

(8).MORAIS, J.P.S.; ROSA, M. de F.; MARCONCINI, J.M. Procedimentos para Análise Lignocelulósica. Documentos 236, Centro Nacional de Pesquisa do 
Algodão, Campina Grande-PB, 2010. Disponível em: <https://www.infoteca.cnptia.embrapa.br/bitstream/d oc/883400/1/DOC236.pdf>. Acesso em: 10 de set. 2015.

(9).RODRIGUES, R.C. Métodos de Análises Bromatológicas de Alimentos: Métodos Físicos, Químicos e Bromatológicos. Documentos 306, Embrapa Clima Temperado, Pelotas-RS, 2010. Disponível em: <http://ainfo.cnptia.embrapa.br/digital/bitstream/item /40059/1/documento-306.pdf>. Acesso em: 10 de Set. 2015.

(10).MENEZES, T. J. B., HENNIES, P. T. Influência do prétratamento do bagaço de cana-de-açúcar com peróxido alcalino e hidróxido de sódio no sistema celulolítico de $A$. níger. Coletânea ITAL, v.21, n.2, p.213-219, 1991.

(11). SANTOS, F.A.; QUEIRÓZ, J.H. de; COLODETTE, J.L.; FERNANDES, S.A.; GUIMARÃES, V.M.; REZENDE, S. T. Potencial da palha de cana-de-açúcar para produção de etanol. Química Nova, v.35, n.5, p.1004-1010, 2012. DOI: 10.1590/S010040422012000500025

(12).IBGE - INSTITUTO BRASILEIRO DE GEOGRAFIA E ESTATÍSTICA. Lavoura Temporária 2013. Disponível em: <http://www.ibge.gov.br/estadosat/temas.php?sigla=t o\&tema=lavouratemporaria2013>. Acesso em: 14 de Set. 2015

(13).CQBAL - Tabelas Brasileiras de Composição de Alimentos para Ruminantes. CQBAL 3.0. Atualizado em 08 de Setembro de 2015. Disponível em:
$<$ http://cqbal.agropecuaria.ws/webcqbal/index.php $>$. Acesso em: 02 de Nov. 2015.

(14).HAMELINCK, C.N.; VAN HOOIJDONK, G.; FAAIJ, A.P.C. Ethanol from lignocellulosic biomass: technoeconomic performance in short-, middle-and long-term. Biomass and Bioenergy, v.28, n.4 p.384-410, 2005. DOI:10.1016/j.biombioe.2004.09.002

(15).LU, J.; LI, Xue Zhi; ZHAO, J.; QU, Y. Enzymatic Saccharification and Ethanol Fermentation of Reed Pretreated with Liquid Hot Water. Journal of Biomedicine and Biotechnology, v.144, p.539-547, 2013. DOI: $10.1155 / 2012 / 276278$

(16). BAK, J. S.; KO, J. K.; HAN, Y. H.; LEE, B. C.; CHOI, I. G.; KIM, K. H. Improved enzymatic hydrolysis yield of rice straw using electron beam irradiation pretreatment. Bioresource Technology, v.100, n.3, p.1285-1290, 2009. DOI: 10.1016/j.biortech.2008.09.010

(17).KRISHNAN, C.; DA COSTA SOUSA, L.; JIN, M.; CHANG, L.; DALE, B. E.; BALAN, V. Alkali-based AFEX pretreatment for the conversion of sugarcane bagasse and cane leaf residues to ethanol. Biotechnology and Bioengineering, v.107, p.441450, 2010. DOI: 10.1002/bit.22824

(18).KARIMI, K.; EMTIAZI, G.; TAHERZADEH, M. J. Ethanol production from dilute-acid pretreated rice straw by simultaneous saccharification and fermentation with Mucor indicus, Rhizopus oryzae, and Saccharomyces cerevisiae. Enzyme Microbiology Technology, v.40, p. 138-144, 2006. DOI: 10.1016/j.enzmictec.2005.10.046 